\title{
Pronunciation and individual item identifications in multiple-item recognition learning
}

\author{
DONALD H. KAUSLER and JOHN E. REMISOVSKY \\ University of Missouri, Columbia, Missouri 65201
}

\begin{abstract}
Item identifications were tested following either pronunciation or no pronunciation of intrapair $R$ and $W$ members of a prior study list. Pronunciation had no effect on $W$ items in terms of identifying either their oldness or their prior pairwise function. However, pronunciation adversely affected identifications of $R$ items in terms of both their oldness and their prior pairwise function. The results were interpreted in terms of both a frequency model and a depth of processing model.
\end{abstract}

Several studies (e. g., Hopkins \& Epling, 1971; Kausler \& Sardello, 1967) have revealed that the overt pronunciation of both right (R) and wrong (W) items retards the acquisition of a multiple-item recognition, or verbal discrimination, learning task. Of interest in the present study is the further effect of pronunciation on individual item identifications following multiple-item recognition learning study phases. The item identification procedure (Kausler, Pavur, \& Yadrick, 1975) calls for an unexpected test phase in which old items, both $\mathbf{R}$ and $\mathrm{W}$, from the prior paired-item study list are exposed individually and are interspersed with new test items. For each test item, the subject decides initially if it is old or new. After each old item, the subject decides further if that item had functioned as $\mathrm{R}$ or $\mathrm{W}$ in the prior study list.

The adverse effect of pronunciation on multiple-item recognition learning per se is readily accounted for by Ekstrand, Wallace, and Underwood's (1966) frequency theory. According to the theory, intrapair discriminations between $\mathrm{R}$ and $\mathrm{W}$ items are mediated by the greater number of frequency units accrued to $R$ items than to their $\mathrm{W}$ item mates. Under standard practice conditions, subjects are likely to respond more to the $R$ item of a given pair than to the $W$ item, thus rapidly accumulating a discriminable frequency advantage for that $\mathrm{R}$ item. By contrast, forced pronunciation of both intrapair members assures a more balanced accumulation of frequency units to $\mathrm{R}$ and $\mathrm{W}$ items. The net effect is to decrease the intrapair disparity in frequency units between $\mathrm{R}$ and $\mathrm{W}$ items, thereby diminishing their discriminability (Kausler \& Sardello, 1967). Traditional frequency theory, however, does not account for the effects of pronunciation on individual item identifications, especially those involving functional decisions. Functional decisions are restricted to a pairwise context in which the relative frequency advantage of $R$ items over $\mathbf{W}$ items is manifested. On the other hand, the signal detection model proposed by Kausler et al. (1975)

This study was supported in part by National Science Foundation Grant BMS75-05007 awarded to the first author. does offer a framework for interpreting the effects of pronunciation on individual item identification.

The model accounts for item decisions in terms of the absolute number of frequency units accrued to the various test items. The distributions of frequency units for $\mathrm{R}$ and $\mathrm{W}$ items following one or more study phases are presumed to be partially overlapping, but with the mean of the $\mathbf{R}$ item distribution exceeding the mean of the $\mathrm{W}$ item distribution. In addition, the mean of each old item distribution exceeds the mean of a noise distribution formed by new test items that were not included in the prior study list. Old-new decisions are then made with respect to a criterion, $\mathrm{C} 1$, that is set at a relatively low level of absolute frequency units. If a test item exceeds $\mathbf{C} 1$, it is identified as being old. Since more $\mathbf{R}$ items than $\mathrm{W}$ items exceed $\mathrm{C} 1$, the hit rate for old item recognition is greater for $R$ items than for $W$ items. Right-wrong decisions are made with respect to a second criterion, C2, that is set at a relatively high level of frequency units. Test items falling above $\mathrm{C} 2$ are identified as having functioned as prior $\mathrm{R}$ items, while test items falling below $\mathrm{C} 2$, but above $\mathrm{C} 1$, are identified as having functioned as prior $\mathrm{W}$ items.

Forced pronunciation of wrong items during study phases should enhance their recognition as old items, relative to the standard, or subject-controlled, rehearsal condition. Pronunciation is likely to increase the number of response-based frequency units accruing to wrong items, thus increasing the number of wrong items that exceed $\mathrm{C1}$. On the other hand, forced pronunciation of $\mathbf{R}$ items should decrease their recognition as old items, again relative to the subject-controlled rehearsal condition. Forced attention to $\mathrm{W}$ items via their overt pronunciation should diminish the opportunity for responding to $\mathrm{R}$ items, thus decreasing the number of $\mathrm{R}$ items that exceed C1. Comparable effects should be manifested with respect to the $\mathrm{C} 2$ criterion. That is, with pronunciation, the number of $\mathrm{W}$ items exceeding $\mathrm{C} 2$ should increase, whereas the number of $\mathrm{R}$ items exceeding $\mathrm{C} 2$ should decrease. The net effect should be a decrease in the hit rate for both $\mathrm{W}$ and $\mathrm{R}$ items in terms of correct functional identifications. 


\section{METHOD}

Subjects

The subjects were 32 students in general psychology classes who fulfilled a course requirement by their participation in this study. They were assigned in randomized blocks to two main groups, one requiring overt pronunciation of both $\mathrm{R}$ and $\mathrm{W}$ items during study phases (Group P) and the other requiring no overt pronunciation (Group NP), and four subgroups of each main group (varying only in specific item content).

\section{Lists}

Each study list contained 23 paired $R$ and $W$ items, 18 of which were experimental pairs and 5 of which were buffer pairs filling primacy and recency positions. The study lists were constructed from two separate sets (A and B) of 36 words. Within each set, the words were paired randomly to form the 18 experimental pairs. The words from the Ekstrand et al. control list provided the initial word pool. Other words were added from various normative sources, with care taken to assure minimal associative relatedness between list components. Two study list variants of Set A (Lists A1 and A2) were prepared by having one member of each pair serve as the $R$ item for one variant and the W item for the other variant. Similarly, two study list variants (Lists B1 and B2) were constructed from Set B. Each of the variants served as the study list for four subjects in Group $P$ and four subjects in Group NP. The test list contained the 18 $\mathrm{R}$ items and the $18 \mathrm{~W}$ items from the experimental pairs of the study list, together with 18 new items. The new items consisted of words randomly selected from the alternate study list set (e. g., B words for subjects receiving A study words).

\section{Procedure}

The procedure closely followed that of Kausler et al. (1975, Experiment I). However, two study trials, rather than one, preceded the single individual item test trial. The $\mathrm{R}$ member of each pair was again identified by being underlined. Spatial position and order effects were controlled across the two study trials. The rate of exposure was $3 \mathrm{sec} /$ pair in each study trial and $6 \mathrm{sec} /$ item in the single test trial. Subjects in Group P were required to pronounce aloud both members of each study pair in left-right sequence, while subjects in Group NP were permitted to control their own rehearsal activities. Finally, all subjects were tested individually.

\section{RESULTS}

Of initial interest is the effect of pronunciation on old item identifications. The hit rate for identifying old test items as old was determined separately for $\mathrm{R}$ and $\mathrm{W}$ items. For $\mathbf{R}$ items the mean and standard deviation were .883 and .149 for Group $P$ and .958 and .066 for Group NP. For W items the mean and standard deviation were .802 and .193 for Group P and .795 and .114 for Group NP. A 2 by 2 mixed analysis of variance (arc sine transformation), with Pronunciation (P vs. NP) as the between-group variable and pairwise Function ( $R$ vs. W) as the within-group variable, revealed a significant main effect for Function $[F(1,30)=31.86, p<.001]$, but not for Pronunciation $[F(1,30)<1]$. In agreement with earlier experiments (e. g., Kausler et al., 1975), the hit rate for old item identification was considerably greater overall for $\mathrm{R}$ items than for $\mathrm{W}$ items. In addition, the Pronunciation by Function interaction effect was significant $[F(1,30)=8.14, p<.01]$. The significant interaction reflected the fact that Group NP's hit rate exceeded Group P's for R items but not for W items.

Of further interest is the effect of pronunciation on the false alarm rate for identifying new test items as old. The mean and standard deviation were .132 and .132 for Group P and .368 and .159 for Group NP. An analysis of variance (arc sine transformation) yielded a significant effect for Pronunciation $[F(1,30)=22.14$, $\mathrm{p}<.001]$. Thus, overtly pronouncing $R$ and $W$ study items markedly reduced the rate of falsely identifying new test items as old.

Especially important is the effect of pronunciation on the identification of old test items in terms of their prior pairwise functions. The absolute hit rates for correctly identifying $\mathrm{R}$ items as right and $\mathrm{W}$ items as wrong were determined for both groups. For Group $P$ the mean and standard deviation were .611 and .197 for $\mathrm{R}$ items and .646 and .156 for W items. For Group NP the mean and standard deviation were .750 and .190 for $R$ items and .649 and .137 for W items. A 2 by 2 mixed analysis of variance (arc sine transformation) indicated a significant Pronunciation by Function interaction effect $[F(1,30)=5.44, p<.05]$. However, neither the main effect for Pronunciation nor the main effect for pairwise Function attained significance $[\mathrm{Fs}(1,30)=2.62$ and 2.11 respectively; ps $>.05]$. The significant interaction effect again reflected the fact that Group NP's hit rate exceeded Group P's for R items but not for W items.

\section{DISCUSSION}

Contrary to the earlier prediction, the present results imply that pronunciation of intrapair members during study phases has little, if any, effect on $\mathrm{W}$ items in terms of their subsequent identifications either as old items or as $\mathrm{W}$ items. With respect to the Kausler et al. (1975) dual criterion model, the proportions of W items exceeding the $\mathrm{C} 1$ and $\mathrm{C} 2$ criteria are seemingly unaffected by the overt pronunciation of those items. The number of frequency units accrued to $W$ items when they are pronounced appears to approximate the number accrued to them under standard rehearsal conditions.

On the other hand, the predicted effect of pronunciation on $R$ items was obtained. That is, pronunciation of intrapair members decreased the hit rate for identifying $R$ items in terms of both oldness and pairwise function. Forced attention to $\mathrm{W}$ items via their overt pronunciation apparently reduces the number of responses to $R$ items that would otherwise occur when subjects control their own rehearsal activities. The adverse effect of pronunciation on multiple-item recognition learning per se results, therefore, from a decrease in the number of response-based frequency units to $R$ items, rather than from an increase in the number of such units accrued to $W$ items.

There is, however, an alternative explanation of the present results. Kausler and Yadrick (1976) noted that the processing of $\mathrm{R}$ items may differ qualitatively, as well as quantitatively, from the processing of $W$ items. One possibility is that $R$ items are processed at a deeper level than W items (Craik \& Lockhart, 1972) under standard practice conditions. The disparity in depth of processing presumably reflects the more elaborative rehearsal given to $\mathbf{R}$ items than to $\mathrm{W}$ items. Forced pronunciation of intrapair members would serve to diminish the opportunity for the elaborative rehearsal of $R$ items, thereby decreasing their discriminability. On the other hand, pronunciation would have little effect on the more shallow level of processing ordinarily given to $\mathrm{W}$ items. 


\section{REFERENCES}

CRAIK, F. I. M., \& LockharT, R. S. Levels of processing: A framework for memory research. Journal of Verbal Learning and Verbal Behavior, 1972, 11, 671-684.

Ekstrand, B. R., Wallace, W. P., \& Underwood, B. J. A frequency theory of verbal discrimination. Psychological Review, 1966, 73, 566-578.

Hopkins, R. H., \& Epling, W. F. Pronunciation and the length of the study interval in verbal discrimination. Journal of Experimental Psychology, 1971, 88, 145-146.
Kausler, D. H., Pavur, E. J., JR., \& Yadrick, R. M. Single-item recognition following a verbal discrimination study trial. Memory \& Cognition, 1975, 3, 135-139.

Kausler, D. H., \& SARdello, R. J. Item recall in verbal discrimination learning as related to pronunciation and degree of practice. Psychonomic Science, 1967, 7, 285-286.

Kausler, D. H., \& YADRICK, R. M. Differential processing of bilingual right and wrong items in multiple-item recognition learning. Journal of Experimental Psychology: Human Learning and Memory, 1976, 2, 284-292.

(Received for publication June 5, 1976.) 